\title{
"OBESITY PARADOX" IN COMORBID STABLE ISCHEMIC HEART DISEASE AND CHRONIC OBSTRUCTIVE PULMONARY DISEASE PATIENTS
}

D01:10.36740/WLek202102119

\author{
Iryna L. Nemish, Ganna Ya. Stupnytska, Oleksandr I. Fediv \\ BUKOVINIAN STATE MEDICAL UNIVERSITY, CHERNIVTSI, UKRAINE
}

\begin{abstract}
The aim: Was to find the possible relationship between spirometry tests, the BODE index (body mass index (BMI), airflow obstruction, dyspnea, and exercise tolerance) with bioimpedance parameters in overweight and class I obese patients.

Materials and methods: 47 patients with stable ischemic heart disease (IHD) (I-II functional class), chronic obstructive pulmonary disease (COPD) (GOLD II, III, IV; groups B, C, D) were divided into 3 groups: G1: 15 normal-weight patients, G2: 15 overweight subjects, and G3: 17 class I obese patients. Spirometry tests, bioimpedance parameters, 6MWT (6-minute walk test) were measured.

Results: FEV1 was significantly higher in overweight $(p=0.033)$ and class I obese $(p=0.049)$ subjects, the BODE index was lower in overweight $(p=0.033)$ and class I obese ( $p=0.037$ ) patients, compared with normal-weight subjects. The statistically significant positive relationship was between BMI and FEV1 and the negative correlation was between BMI and the BODE index in all groups of patients $(p<0.05)$.

Conclusions: In our study, we found better FEV1, 6MWT, the BODE index, the statistically significant association between FEV1 and the BODE index with BMI in overweight and class I obese patients. That's why we can suppose the presence of the "obesity paradox" in comorbid overweight or class I obese stable IHD, COPD patients.
\end{abstract}

KEY WORDS: COPD, obesity, spirometry

Wiad Lek. 2021;74(2):278-281

\section{INTRODUCTION}

Nowadays, the impact of obesity on spirometry tests and quality of life in comorbid patients with stable IHD and COPD is very actuality $[1,2,3]$. Numerous studies have shown that low body BMI is an independent predictor of mortality in COPD patients [4]. Overweight or class I obese COPD subjects had a better prognosis and fewer number of exacerbations $[1,2,3]$. The results of large meta-analyses had shown the lower overall and cardiovascular mortality in overweight or obese stable IHD patients $[5,6]$. Therefore, the protective role of class I obesity on the spirometry tests and quality of life remains interesting, especially in comorbid stable IHD, COPD patients.

\section{THE AIM}

The aim of our study was to find the possible relationship between spirometry tests, the BODE index with bioimpedance parameters in overweight and class I obese patients.

\section{MATERIALS AND METHODS}

47 patients with stable IHD (I-II functional class), COPD GOLD II, III, IV; group B, C, D; were included in the study. The mean age was $62.22 \pm 11.96$. Among all patients,
$55.32 \%$ were male and $44.68 \%$ - female. The diagnosis and stage of COPD were established according to the Global Initiative for Chronic Obstructive Lung Disease (GOLD) recommendations [7]. The diagnosis of stable IHD was performed in accordance with the European Society of Cardiology (ESC) guidelines [8]. Main inclusion criteria were: aged from 45 to 70 , signed informed volunteer study consent, diagnosis of COPD with post-bronchodilator $\mathrm{FEV}_{1} / \mathrm{FVC}<0.70$, grade II, III, IV of bronchial obstruction (according to GOLD 2010) and groups B, C, D (as to GOLD 2011) and the presence of stable IHD.

We divided all patients into 3 groups: G1: 15 patients with stable IHD, COPD, and $18.5<\mathrm{BMI}<24.9, \mathrm{G} 2: 15$ overweight subjects $(25<\mathrm{BMI}<29.9)$, and G3: 17 class I obese patients $(30.0<\mathrm{BMI}<34.9)$. We used BTL - Spiro Pro computer spirograph (UK) to assess spirometry tests after a short-acting bronchodilator test (400 $\mathrm{mg}$ of salbutamol) in all groups of patients. We used a portable apparatus (TANITA BC-601, Japan) to determine all bioimpedance parameters. Also, all patients completed the CAT test and SGRQ to assess their overall health and quality of life. Dyspnea severity was performed using a Modified Medical Research Council Council (mMRC) scale. We used 6MWT to assess the submaximal level of exercise capacity. BMI, $\mathrm{FEV}_{1}$, $\mathrm{mMRC}$, and 6MWT were used to estimate the BODE 
Table I. Baseline characteristics of comorbid stable IHD and COPD patients with different BMI categories

\begin{tabular}{|c|c|c|c|c|}
\hline Group & $\begin{array}{c}\text { Stable IHD, COPD, and } \\
18.5<\text { BMI }<24.9 \\
(\mathrm{~N}=15)\end{array}$ & $\begin{array}{c}\text { Stable IHD, COPD, and } \\
25<\text { BMI }<29.9 \\
(\mathrm{~N}=15) \\
\end{array}$ & $\begin{array}{c}\text { Stable IHD, COPD, and } \\
30.0<\text { BMI }<34.9 \\
(\mathrm{~N}=17) \\
\end{array}$ & $P$ value \\
\hline $\begin{array}{c}\text { male } \\
\text { female }\end{array}$ & $\begin{array}{l}11(87.5 \%) \\
4(12.5 \%)\end{array}$ & $\begin{array}{l}6(40 \%) \\
9(60 \%)\end{array}$ & $\begin{array}{l}9(52.94 \%) \\
8(47.06 \%)\end{array}$ & \\
\hline Age (years) & $67.53 \pm 11.3$ & $64.67 \pm 10.75$ & $55.94 \pm 9.27$ & $p_{3}=0.007$ \\
\hline Pack-years, $\mathrm{M} \pm \mathrm{SD}$ & $19.3 \pm 15.53$ & $6.67 \pm 9.0$ & $13,294 \pm 16,26$ & $p_{1}=0.015$ \\
\hline $\begin{array}{l}\text { GOLD II } \\
\text { GOLD III } \\
\text { GOLD IV } \\
\text { group B } \\
\text { group C } \\
\text { group D }\end{array}$ & $\begin{array}{c}5(33.3 \%) \\
6(40 \%) \\
4(26.7 \%) \\
5(33.3 \%) \\
4(26.7 \%) \\
6(40 \%)\end{array}$ & $\begin{array}{l}7(46.66 \%) \\
4(26.67 \%) \\
4(26.67 \%) \\
7(46.66 \%) \\
4(26.67 \%) \\
4(26.67 \%)\end{array}$ & $\begin{array}{c}5(29.41 \%) \\
10(58.82 \%) \\
2(11.77 \%) \\
5(29.41 \%) \\
8(41.18 \%) \\
5(29.41 \%)\end{array}$ & \\
\hline BMI $\left(\mathrm{kg} / \mathrm{m}^{2}\right)$ & $22.6 \pm 1.39$ & $27.8 \pm 1.35$ & $33.66 \pm 2.5$ & $\begin{array}{l}\mathrm{p}_{1}<0.0001 \\
\mathrm{p}_{2}<0.0001 \\
\mathrm{p}_{3}<0.0001\end{array}$ \\
\hline body fat percentage & $23.11 \pm 5.7$ & $32.83 \pm 6.07$ & $36.2 \pm 9.69$ & $\begin{array}{l}\mathrm{p}_{1}<0.0001 \\
\mathrm{p}_{3}<0.0001\end{array}$ \\
\hline muscle mass, $\mathrm{kg}$ & $51.87 \pm 7.88$ & $49.15 \pm 7.13$ & $52.8 \pm 8.59$ & NS \\
\hline visceral fat level & $9.13 \pm 3.04$ & $11.13 \pm 4.3$ & $17.65 \pm 4.26$ & $\begin{array}{l}\mathrm{p}_{2}<0.0001 \\
\mathrm{p}_{3}<0.0001\end{array}$ \\
\hline CAT score & $23.2 \pm 2.73$ & $21.78 \pm 1.64$ & $22.12 \pm 2.4$ & NS \\
\hline $\begin{array}{l}\text { SGRQ symptoms } \\
\text { score }\end{array}$ & $60.88 \pm 9.58$ & $57.24 \pm 8.7$ & $56.64 \pm 7.55$ & NS \\
\hline $\begin{array}{c}\text { SGRQ } \\
\text { activity score }\end{array}$ & $50.48 \pm 11.16$ & $53.53 \pm 13.31$ & $47.31 \pm 7.18$ & $p_{2}=0.033$ \\
\hline $\begin{array}{c}\text { SGRQ } \\
\text { impact score }\end{array}$ & $42.87 \pm 6.2$ & $44.3 \pm 4.56$ & $43.21 \pm 6.02$ & NS \\
\hline $\begin{array}{c}\text { SGRQ } \\
\text { total score }\end{array}$ & $55.1 \pm 8.16$ & $51.74 \pm 6.2$ & $52.83 \pm 5.48$ & NS \\
\hline $\begin{array}{l}\text { post-bronchodilator, } \\
\text { FEV }_{1}\end{array}$ & $44.04 \pm 11.56$ & $52.78 \pm 13.98$ & $52.94 \pm 12.45$ & $\begin{array}{l}\mathrm{p}_{1}=0.033 \\
\mathrm{p}_{3}=0.049\end{array}$ \\
\hline mMRC score & $2.27 \pm 0.7$ & $1.67 \pm 1.05$ & $2.0 \pm 0.87$ & $p_{1}=0.033$ \\
\hline 6MWT (meters) & $230.33 \pm 63.6$ & $284.33 \pm 71.83$ & $287.35 \pm 74.84$ & $\begin{array}{l}p_{1}=0.023 \\
p_{3}=0.018\end{array}$ \\
\hline BODE index & $5.00 \pm 2.14$ & $3.13 \pm 2.6$ & $3.47 \pm 2.32$ & $\begin{array}{l}p_{1}=0.033 \\
p_{3}=0.037\end{array}$ \\
\hline Modified BODE index & $5.27 \pm 2.66$ & $3.73 \pm 2.9$ & $5.0 \pm 2.24$ & $\mathrm{p}_{2}=0.027$ \\
\hline
\end{tabular}

Values are $\mathrm{M} \pm \mathrm{SD}$ or $\%$; NS: not significant.

Note 1. p1 - the difference between stable IHD, COPD patients with $18.5<\mathrm{BMI}<24.9$, and stable IHD, COPD patients with $25<\mathrm{BMI}<29.9$.

Note 2. p2 - the difference between stable IHD, COPD patients with $25<\mathrm{BMI}<29.9$, and stable IHD, COPD patients with $30.0<\mathrm{BMI}<34.9$.

Note 3. p3 - the difference between stable IHD, COPD patients with $18.5<\mathrm{BMI}<24.9$, and stable IHD, COPD patients with $30.0<$ BMI $<34.9$.

index. The study meets the requirements of the Helsinki Declaration of the World Medical Association «Ethical principles for medical research involving human subjects as the object of study» opinion of the Committee on bioethics SHEI «Bukovinian State Medical University» of MPH of Ukraine №5/2020.

Statistical analyses were performed on a personal computer using SPSS Statistica 23. Quantitative data are presented as $\mathrm{M} \pm \mathrm{SD}$, where $\mathrm{M}$ is the mean, $\mathrm{SD}$ - standard deviation. Normality was verified using the Shapiro-Wilk test. Non-parametric the Mann-Whitney U test was used to compare differences between each of two independent groups.

\section{RESULTS}

Clinical characteristics all groups of patients are presented in Table I.

We analyzed the results of bioimpedance analysis in all groups of patients. Body fat percentage was significantly 
higher $(\mathrm{p}<0.0001)$ in overweight or class I obese stable IHD, COPD patients compared with normal-weight subjects. There were no statistically significant differences between compared groups in muscle mass. The results of subjective assessment quality of life (CAT test, SGRQ) between all groups of patients were not statistically significant. The value of post-bronchodilator $\mathrm{FEV}_{1}$ was significantly higher in overweight stable IHD, COPD patients $(\mathrm{p}=0.033)$ and class I obese subjects $(\mathrm{p}=0.049)$ compared with normal-weight patients. Also, overweight subjects had significantly lower mMRC score $(\mathrm{p}=0.033)$ compared with the first group. There was no significant difference in the mMRC score between class I obese patients and normal-weight subjects $(\mathrm{p}>0.05)$. The total distance walked in meters $(6 \mathrm{MWT})$ was significantly higher in the second $(\mathrm{p}=0.023)$ and third $(\mathrm{p}=$ 0.018 ) groups of patients compared with the normal-weight subjects. Patients with normal BMI had significantly higher the BODE index compared with overweight $(\mathrm{p}=0.033)$ and class I obese subjects $(\mathrm{p}=0.037)$.

Also we found a statistically significant positive correlation between BMI and FEV in the first $(\mathrm{r}=0.546 ; \mathrm{p}=$ $0.035)$, second $(r=0.594 ; p=0.02)$ and third $(r=0.738 ; p=$ $0.001)$ groups of patients. The negative correlation was between BMI and the BODE index in the first $(r=-0.565$; $\mathrm{p}=0.028)$, second $(\mathrm{r}=-0.682 ; \mathrm{p}=0.005)$ and third $(\mathrm{r}=$ $-0.568 ; \mathrm{p}=0.017$ ) groups. However, we didn't find a statistically significant correlation between the muscle mass and $\mathrm{FEV}_{1}$ and the BODE index ( $\left.\mathrm{p}>0.05\right)$.

\section{DISCUSSION}

Therefore, in our study, we have obtained results close to the data of numerous scientific publications about the role of overweight or class I obesity in stable IHD, COPD patients $[9,10,11]$. The inverse correlation was found between BMI and mortality in the meta-analysis of 22 studies involving 21150 COPD patients. Also, in this study overweight or obese (BMI $\geq 30$ ) patients had a lower mortality rate compared to normal-weight subjects [9]. The results of another meta-analysis showed the impact of bodyweight deficiency and obesity on survival in COPD patients. Mortality rates were highest in bodyweight deficiency $(\mathrm{BMI}<21.75 \mathrm{~kg} / \mathrm{m} 2)$ subjects. Survival rates were the best in patients with $\mathrm{BMI}=$ $30 \mathrm{~kg} / \mathrm{m}^{2}[10]$. Also, the results of $6 \mathrm{MWT}$ showed that, when obese COPD patients increased the distance on 1 meter, they had a better survival rate during the 26 months of the experiment [12]. The role of the BODE index is also very significant in assessing COPD patients. As to another study, the BODE index in class I obese patients was significantly lower compared with normal-weight subjects [13]. In our study, the BODE index was the highest in normal-weight patients compared to the second and third groups of patients. There was also a negative correlation between BMI and the BODE index. According to these studies, we can assume a better prognostic survival in overweight or class I obese subjects.

Also, in an 11-year study, involving 40,000 confirmed angiographic IHD subjects, the lowest mortality rate was in patients with $27.5<\mathrm{BMI}<30 \mathrm{~kg} / \mathrm{m} 2$, but the presence of class III obesity increased mortality in twice [14]. In another study with 4,400 IHD participants was found, that obese patients (BMI $>30)$, despite a large number of risk factors, had better 7-year survival rates compared to the normal-weight subjects [15].

As a summary, we concluded that the results of our study were similar to the data of previous scientific publications regarding the protective value of overweight or class I obesity in comorbid stable IHD, COPD patients. The value of post-bronchodilator $\mathrm{FEV}_{1}, 6 \mathrm{MWT}$ were significantly higher in the second and third groups compared to the first. The mMRC dyspnea severity and the BODE index were significantly lower in overweight or class I obese patients. Also, we noted the existence of a statistically significant positive relationship between $\mathrm{BMI}$ and $\mathrm{FEV}$ and a negative correlation between BMI and the BODE index in all groups of patients. Previous researches had described the protective role of class I obesity or overweight separately in COPD patients and IHD subjects. But in our study the participants were comorbid. That's why maybe we can interpret the results of our study as the summary effect of the "obesity paradox".

\section{CONCLUSIONS}

Therefore, analyzing the literature and the results of our study, we can assume the "obesity paradox" in stable IHD, COPD patients. The value of post-bronchodilator $\mathrm{FEV}_{1}$ and the prognostic survival score (the BODE index) in overweight or class I obese patients were specifically related to BMI. In our study, we did not find significantly higher muscle mass values in overweight or class I obese patients. But we noted a tendency to increase this parameter in class I obese patients. Maybe the results of the study will be another if the patients will perform muscle-strengthening exercises during some period with further assessment of spirometry tests and all bioimpedance parameters.

Nowadays, the main cause of the "obesity paradox" remains relevant and discussable in patients with chronic diseases.

\section{REFERENCES}

1. Prudente R., Franco E.A.T., Mesquita C.B. et al. Predictors of mortality in patients with COPD after 9 years. Int J Chron Obstruct Pulmon Dis. 2018;13:3389-98.

2. Tsai Y.H., Wang C.C., Kuo P.H. Impact of overweight and obesity on acute exacerbations of COPD - subgroup analysis of the Taiwan Obstructive Lung Disease cohort. Int J Chron Obstruct Pulmon Dis. 2017;12(12):2723-29.

3. Geva S., Yaakob M., Kalchiem-Dekel 0. The association between obesity and chronic obstructive pulmonary disease (COPD). Harefuah. 2016;55(9):554-558.

4. McDonald M.N., Wouters E.F.M., Rutten E. et al. It's more than low BMI: prevalence of cachexia and associated mortality in COPD. Respir Res. 2019;20(1):100.

5. Oreopoulos A., McAlister F.A., Kalantar-Zadeh K. et al. The relationship between body mass index, treatment, and mortality in patients with established coronary artery disease: a report from APPROACH. Eur Heart J 2009;30:2584-2592. 
6. Antonopoulos A.S., Oikonomou E.K., Antoniadeset C. et al. From the BMI paradox to the obesity paradox: the obesity-mortality association in coronary heart disease. Obes Rev. 2016;17(10):989-1000.

7. Vestbo J., Hurd S.S., Agustí A. et al. Global strategy for the diagnosis, management and prevention of chronic obstructive pulmonary disease, GOLD executive summary. Am J Respir Crit Care Med 2013;187:347-65.

8. Montalescot G., Sechtem U., Achenbach S. et al. 2013 ESC guidelines on the management of stable coronary artery disease: the Task Force on the management of stable coronary artery disease of the European Society of Cardiology. Eur Heart J 2013;34:2949-3003.

9. Cao C., Wang R., Wang J. et al. Body mass index and mortality in chronic obstructive pulmonary disease: a meta-analysis. PLoS One. 2012;7(8):e43892. doi: 10.1371/journal.pone.0043892.

10. Guo Y., Zhang T., Wang Z. et al. Body mass index and mortality in chronic obstructive pulmonary disease. Medicine (Baltimore). 2016;95(28):e4225. doi: 10.1097/MD.0000000000004225.

11. Divo M.J., Cabrera C., Casanova C. et al. Comorbidity Distribution, Clinical Expression and Survival in COPD Patients with Different Body Mass Index. Chronic Obstr Pulm Dis. 2014;1(2):229-238. doi: 10.15326/ jcopdf.1.2.2014.0117.

12. Altinoz H., Adiguzel N., SalturkC. et al. Obesity might be a good prognosis factor for COPD patients using domiciliary noninvasive mechanical ventilation. Int J Chron Obstruct Pulmon Dis. 2016;11:1895-1901.

13. Barbarito N., De Mattia E. Grading the severity of obstruction in patients with Chronic Obstructive Pulmonary Disease and morbid obesity. Monaldi Arch Chest Dis. 2013;79(3-4):121-7.

14. Azimi A., Charlot M.G., Torp-Pedersen C. et al. Moderate overweight is beneficial and severe obesity detrimental for patients with documented atherosclerotic heart disease. Heart 2013;111:1104-1110.

15. Hamer M., Stamatakis E. Overweight and obese cardiac patients have better prognosis despite reporting worse perceived health and more conventional risk factors. Prevent Med 2013;57:12-16.

\section{ORCID and contributionship:}

Iryna L. Nemish: 0000-0002-8138-221X ${ }^{B, C, D}$

Ganna Ya. Stupnytska: 0000-0002-9835-387X A,C,E

Oleksandr I. Fediv: 0000-0003-0108-2565 B,E,

\section{Conflict of interest:}

The Authors declare no conflict of interest.

\section{CORRESPONDING AUTHOR \\ Iryna L. Nemish \\ Bukovinian State Medical University \\ 2 Teatralna square, 58000 Chernivtsi, Ukraine \\ tel: 0982755087 \\ e-mail:iranemish@ukr.net}

Received: 07.04 .2020

Accepted: 20.11 .2020

A - Work concept and design, B - Data collection and analysis, $\mathbf{C}$ - Responsibility for statistical analysis, D - Writing the article, $\mathbf{E}$ - Critical review, $\mathbf{F}$ - Final approval of the article 